\title{
JOSÉ DOS REIS CARVALHO: OBRAS NATURALÍSTICAS, ETNOGRÁFICAS E NATUREZAS MORTAS
}

Heitor de Assis Júnior ${ }^{1}$

\section{Resumo}

Esta comunicação traz informações a respeito do pintor José dos Reis Carvalho e sua produção artística.Tem como linha de orientação suas relações com Debret e a Comissão Científica de Exploração. Este pintor apresenta vínculos intelectuais com Rugendas e também sofreu influências das obras de cientistas viajantes como von Martius. A confrontação de imagens permite ilustrar relações entre as obras do artista e aquelas de seus precursores. Pesquisas em diversas bibliotecas e museus permitiram encontrar evidências de sua familiaridade com o desenho científico em representações suas da flora e fauna brasileiras, ou ainda, em diversas naturezas mortas que exibem com grande fidelidade animais, flores e frutos.

Palavras-chave: Arte Brasileira, Ilustrações Naturalísticas, Reis Carvalho, Pinturas de Viajantes.

\begin{abstract}
This communication presents some information about the painter José dos Reis Carvalho and his artistic production. Its orientation line deals with the painter's relations with Debret and the Scientific Exploration Commission. Besides showing intellectual connection with Rugendas, José dos Reis Carvalho was also influenced by the works of traveling scientists such as Von Martius. The comparison of images allows us to illustrate relations between Carvalho's works and those of his forerunners. Researches at several libraries and museums have made it possible to find evidences of the painter's familiarity with scientific drawings which portray Brazilian flora and fauna as well as his still life paintings which accurately depict animals, flowers and fruits.
\end{abstract}

Key-words: Brazilian Art, Naturalistic Illustrations, Reis Carvalho, Travellers’ Paintings.

\section{Introdução e justificativa}

A escolha do pintor e desenhista José dos Reis Carvalho como núcleo desta pesquisa surgiu de seu interesse pelas ilustrações naturalísticas, objetos de estudo também em minha dissertação de Mestrado intitulada "Relações de von Martius com Imagens Naturalísticas e Artísticas do Século XIX ${ }^{20}$.

Durante aquela pesquisa, pode ser constatada a identificação de José dos Reis Carvalho com os naturalistas viajantes do século XIX, através de suas pranchas com diferentes espécies de plantas e insetos e pela sua participação na primeira expedição científica genuinamente brasileira intitulada "Comissão Científica de Exploração" ocorrida de 1859 a 1861 no estado do Ceará, promovida pelo IHGB e apoiada pelo então imperador, D. Pedro II.

\footnotetext{
${ }^{1} \mathrm{IFCH}-\mathrm{UNICAMP}$

2 ASSIS JÚNIOR, 2004. Disponível para download no site da biblioteca da Unicamp: http://libdigi.unicamp.br/document/?code $=$ vtls000316130
} 
Entre as imagens importantes para esta pesquisa, podem ser citadas as constantes dos catálogos das Exposições da Academia Imperial de Belas Artes a partir daquela organizada em 1826 por Debret e nas oficiais de 1829, 1830, 1841, 1843, 1848, 1849, 1861, 1865 e 1884.

A abordagem das ilustrações naturalísticas é imprescindível para escrever sobre História da Arte Brasileira do século XIX e Reis Carvalho é um importante capítulo ainda desconhecido, constituindo um campo aberto às investigações.

O patrimônio mais enaltecido da nação brasileira, ou seja, sua natureza, foi muito representado por viajantes estrangeiros em imagens naturalísticas através de aquarelas e desenhos ressaltando a flora e a fauna tropicais. Vale ressaltar que sem os métodos artificiais de captação de imagens, nada mais necessário que a presença do pintor desenhista dentro da natureza. A participação posterior do naturalista permitia o acréscimo de detalhes através de desenhos, necessários para a identificação taxonômica do espécime a ser ressaltado, ou pelo menos, o naturalista indicaria ao artista os detalhes que este deveria acrescentar à pintura aquarelada. Isto posto, percebe-se que o artista passou a ter uma nova função fora das academias e estúdios artísticos, sendo incluído num novo mercado de trabalho de cunho científico. A valorização da natureza tropical muito presente na literatura romântica brasileira, ao mesmo tempo majestosa e assustadora, revela sentimentos do sublime através de detalhes dramáticos como a natureza retorcida dos troncos e ramos, seu envolvimento por trepadeiras parasitas e epífitas ${ }^{3}$, como por exemplo, cipós, samambaias, orquídeas etc. Tons amarelados, ocres e esverdeados dão à floresta seu caráter quase medonho e, porque não dizer, mágico. Homens minúsculos em trajes a rigor passam a ser representados em meio à floresta exaltando a nação dos trópicos que interage com a civilização de origem européia.

Essa nova forma de enxergar a natureza se opõe e quase critica a ação predatória anteriormente promovida pelos colonizadores que tinham a natureza como obstáculo para a produção agrária. A natureza passa a ser valorizada esteticamente e espiritualmente e não mais política e economicamente, como se fosse um entrave para o progresso econômico que deveria sustentar a metrópole.

Ocorre uma preocupação maior com a Teoria do Dessecamento que, desde o século XVIII, e agora no XIX, atribui à devastação ambiental a responsabilidade pela diminuição das chuvas e dos mananciais, cujas carências eram em parte responsáveis pelas pestes que assolavam a Corte nos novecentos.

\section{Resultados}

Num levantamento bibliográfico preliminar, muito pouco pode ser encontrado sobre a biografia José dos Reis Carvalho e sua obra. Pesquisas posteriores em diversas bibliotecas e museus permitiram encontrar vestígios de sua familiaridade com o desenho científico em representações suas da flora e fauna brasileiras, ou ainda, em diversas pinturas de natureza morta, nas quais representou com grande fidelidade flores e frutos.

No ponto em que se encontra esta pesquisa foram encontradas 154 obras, entre desenhos e pinturas deste artista que foram citadas em diferentes bibliografias, bibliotecas e museus, sendo que deste total, 52 já foram digitalizados a partir de originais e, algumas, em

\footnotetext{
3 Plantas parasitas sugam seiva da planta hospedeira, as epífitas não trazem prejuízos, apenas se beneficiam da luminosidade encontrada nos estratos superiores, isto é, no alto dos troncos das hospedeiras.
} 
citações bibliográficas. Vale ressaltar que coleções particulares e novas pesquisas em museus e bibliotecas, deverão incrementar ainda mais este já considerável conjunto de obras, ainda tão pouco conhecido e divulgado.

No quase incógnito Reis Carvalho pode-se perceber a influência de celebridades da História da Arte como Rugendas e Debret, sendo que, na obra deste último, Voyage Pittoresque et Historique au Brésil ${ }^{4}$, talvez o próprio aluno também tenha influenciado o mestre, fato este que pretende ser investigado no decorrer desta pesquisa.

Em seus desenhos aquarelados cenas populares urbanas do Rio de Janeiro, nas quais escravos e burgueses interagem, constituem um legado das ilustrações de Debret. Este fato pode ser observado em algumas ilustrações.

Bica dos Marinheiros. Aquarela/papel - 1851. 16,5 x 22,8 cm, Assinada: J. R. Carvo e obra de Debret, Barbeiros ambulantes (DEBRET, 1834-9).

O próprio Debret descreve a sua obra: "A cena aqui desenhada passa-se nas proximidades do Largo do Palácio, perto do mercado de peixe. Dois negros de elite estão sentados no chão; a medalha do que está ensaboado, indica sua função na alfândega. Ambos aguardam, numa imobilidade favorável a seus barbeiros, o momento de remunerar-lhes a habilidade com a módica importância de dois vinténs. A forma e o ornato dos chapéus, datam de época da fundação do Império brasileiro. Com efeito, naquele momento de entusiasmo nacional, as freqüentes revistas e paradas introduziram o gosto pelas coisas militares em todas as classes da população e os negros, naturalmente imitadores, transformaram o schako em um chapéu de palha grotesco ornado de uma roseta nacional e dois galões pintados a óleo; uma pena de pássaro substitui o penacho do uniforme”. (DEBRET, 1978, 210)

Nas duas obras, a presença de barbeiros e fregueses, sendo que todos são negros, tanto aqueles que trabalham, quanto aqueles que pagarão pelo serviço. Estas pinturas de caráter etnográfico mostram que em 1851, o aluno Reis Carvalho foi influenciado pelas ilustrações presentes na obra do mestre, Voyage Pittoresque publicada entre 1834 e 1839.

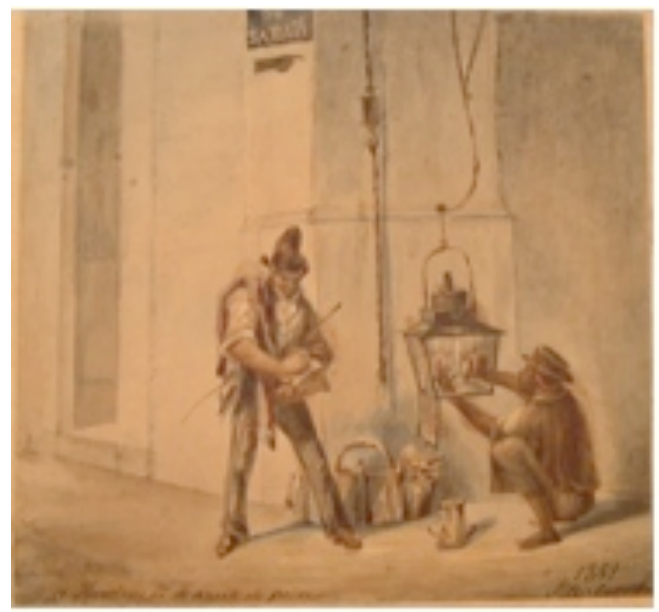

$A$ ilaminacäo de az̧eite de peixe. Aquarela/papel - $1851.17 \times 18,5 \mathrm{~cm}$

Assinada: Je. Reis Carvalho.

${ }^{4}$ DEBRET, 1834-1839. 


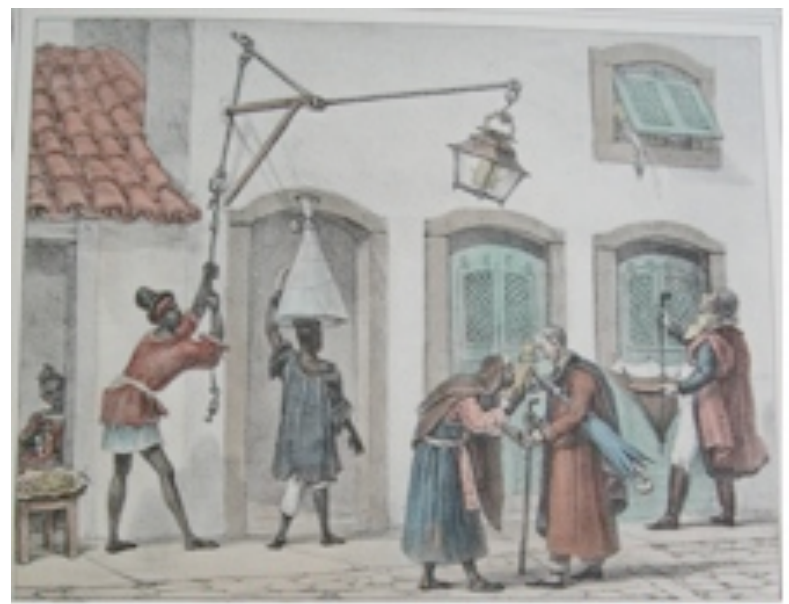

Primeiras oxupapōes da manbã. Pedintes. (DEBRET, 1834-9)

“O lampião colocado ao lado da fábrica de balas recebe nessa hora os cuidados diários de limpeza confiados a empregados subalternos, cujo cheiro infecto revela aos transeuntes tratar-se de negros a serviço do empreiteiro da iluminação da cidade. Não é menos útil evitarse igualmente, no correr do dia, a proximidade dos armazéns da administração que constituem, nas horas de abertura, um foco de emanação dos miasmas perniciosos do azeite de baleia." (DEBRET, 1978, 154.)

Ambas as imagens mostram serviçais negros pertencentes às empreiteiras em sua atividade ligada à iluminação pública. Naquela época o azeite de baleia era utilizado como combustível e deveria ser sistematicamente reabastecido. É interessante observar que tanto na imagem de Debret como na de Reis Carvalho, há uma preocupação com os mecanismos de funcionamento e do reabastecimento das luminárias, além dos materiais que as compõem. Este tipo de preocupação está presente nas obras artísticas de Reis Carvalho realizadas mais tarde, entre 1859 e 1861, durante a Comissão Científica Exploratória, em suas ilustrações de casas, cercas, moinhos e igrejas. À esquerda da imagem dos dois autores, nota-se a presença de estabelecimento de comércio. $\mathrm{Na}$ de Reis Carvalho uma placa aponta para a venda de sabão.

As imagens dos dois artistas revelam preocupação com os materiais e com os detalhes da confecção de vestimentas e instrumentos.

\section{Participação de José dos Reis Carvalho na comissão Científica de Exploração}

O Instituto Histórico e Geográfico Brasileiro foi criado em 1838 e acolheu importantes personagens da cultura literária, artística e científica do país, constituindo-se numa entidade de cunho generalista visando à construção da História Nacional Brasileira, como impunha o momento, sem prejuízo das especializações no setor da historiografia. ${ }^{5}$

A partir de 15 de dezembro de 1849, o próprio Imperador Pedro II passou a presidir regularmente seus trabalhos. Em 30 de maio de 1856, Manuel Ferreira Lagos fez um discurso no qual afirmava a necessidade de uma expedição genuinamente brasileira e utilizou como argumento, os equívocos cometidos por diversas expedições, por naturalistas e por muitos viajantes que estiveram no Brasil desde o século XVIII.

\footnotetext{
${ }^{5}$ BRAGA, 1962:15.
} 
Durante um ano e oito meses os naturalistas e engenheiros percorreram o Ceará, incluindo no percurso, pequenas incursões pelas províncias de Pernambuco, Paraíba, Rio Grande do Norte e Piauí.

Além de Reis Carvalho, o botânico, Francisco Freire Alemão também desenhou espécimes vegetais coletados e detalhando suas flores e frutos, realizou cerca de seiscentos esboços se encontram na Seção de Manuscritos da Biblioteca Nacional,.

Outro foco de investigação desta pesquisa será a influência de Freire Alemão nas escolhas dos motivos das obras pictóricas e desenhos Reis Carvalho.

Freire Alemão trocou correspondências com von Martius que publicava na época a sua Flora Brasiliensis que, com o patrocínio de Dom Pedro II do Brasil, Fernando I, da Áustria e Luís I, da Baviera, teve sua publicação iniciada em 1840 e levaria 66 anos para ser concluída. O conjunto da obra é composto por de 130 fascículos que resultaram em 40 partes reunidas em 15 volumes ricamente ilustrados. O próprio Karl Friedrich vo Martius (1794-1868) dirigiu sua publicação de 1840 a 1868, ano de sua morte. Martius em carta dirigida a Manuel Araújo Porto-Alegre, em agosto de 1859, revelou seu interesse pela expedição brasileira e solicitou a remessa de resultados para poder divulgá-los. No entanto, Freire Alemão tencionava envia-los somente após publicação temendo perder a primazia da autoria das novas espécies descobertas durante a expedição.

Reis Carvalho elaborou uma série de desenhos e pinturas compreendendo motivos diversos, sendo que a influência de seu mestre Debret mais uma vez se faz presente. No caso de sua Estação de carros no sertão que pode ser comparada ao Acampamento dos Viajantes de Debret, embora a primeira esteja ambientada no agreste cearense e a segunda junto à Mata Atlântica, ambas retratam a forma de transporte mais comum nessas viagens pelo interior do Brasil: carroças puxadas por burros.

Esta imagem parece estabelecer um paralelo da expedição brasileira com as viagens de naturalistas europeus, ainda mais, quando confrontada com outra do acampamento dos viajantes em meio à mata na qual a comissão zoológica é identificada com uma inscrição em um baú localizado em plano quase frontal.

Pode-se notar que Debret destaca os detalhes da montagem do acampamento utilizando-se das cargas e mesmo do aparelhamento dos animais, com a finalidade de proteger o grupo viajante. Nota-se que Reis Carvalho seguiu seu exemplo nesta sua obra, assim como, em diversas outras, onde também podem ser observados e mesmo chega a descrever os materiais utilizados em construções de casas, igrejas, cercas, moinhos de vento e outros aparatos utilizados pelos sertanejos. Uma de suas belíssimas imagens é a sua Casa de pau-a-pique em ruinas que, além de seu colorido e plantas que a recobrem, exibe com clareza a disposição dos diferentes materiais utilizados em sua construção.

\section{Dados Biográficos de José dos Reis Carvalho}

A biografia de José dos Reis Carvalho mostra-se repleta de lacunas e dados contraditórios. Em pesquisas iniciais a respeito deste fascinante artista brasileiro, algumas informações sugerem possibilidades bastante concretas de maiores esclarecimentos.

Informações sobre a Exposição Memória Cearense promovida pelo Museu Histórico Nacional sugerem que "apesar de não terem sido encontrados dados referentes ao nascimento e morte de José dos Reis Carvalho, deduz-se que ele teve uma vida profissional atuante 
bastante longa, cerca de 60 anos, comprovados através de citação feita por Debret em 1824 e de trabalhos datados de $1884 "$.

No Serviço de Documentação da Marinha existe um Livro de Registro das Cartas dos Lentes e Professores da Academia das Guardas Marinhas, nas páginas 10 e 11, consta em grafia manuscrita, no dia 14 de outubro de 1828 a nomeação de José dos Reis Carvalho como "professor substituto da cadeira de desenho da Academia das Guardas Marinhas (...) percebendo o mesmo ordenado do antecessor". Em 23 de abril de 1831 ${ }^{7}$, por ocasião do falecimento de José Christo Moreira, assume Reis Carvalho o seu lugar como Professor titular recebendo o honorário de quatrocentos mil réis por ano. "Por decreto de 10 de maio foi jubilado; e por Aviso da Secretaria d'Estado de 11 dito, se ordenou, que continuasse em exercício, percebendo annualmente a gratificação eqüivalente á metade do respectivo ordenado" (sic).

José dos Reis Carvalho deve ter saído da Escola Imperial da Marinha entre 1865 e 1872, pois, no Almanak da Marinha ${ }^{8}$ de 1866, aparece como segundo tenente honorário e professor de desenho de figura e paisagem. A citação no Almanak de 1866 pode ter sido decorrente de sua substituição no final do ano (14 de novembro) de 1865 e impossibilidade de correção no momento da publicação.

Nos Almanaks de 1869 e 70 (os Almanaks de 1867 e 1868 não foram encontrados no Serviço de Documentação da Marinha), tal função passa a ser exercida por Antônio José da Rocha e desaparece o nome de Reis Carvalho. A admissão de Rocha como professor adjunto ocorreu por decreto de 16 de novembro de 1858 e como professor (titular) por decreto de 14 de novembro de 1865, data esta, que pode ser coincidente ou próxima da substituição de José dos Reis Carvalho.

Fato confirmado no prospecto e da Exposição Memória Cearense, onde Reis Carvalho é citado como tendo sido "professor da Escola Imperial da Marinha no período de 1828 a $1865 "$ ".

O ano de 1884 aparece junto às duas assinaturas presentes na obra Os parasitas do MNBA; se for levado em conta o nascimento em 1800, proposta por $\mathrm{ADES}^{9}$, indicaria que José dos Reis Carvalho estaria trabalhando ainda aos 84 anos, portanto, em idade bastante avançada. No catálogo da Exposição de 1884, está presente a citação da obra Os parasitas do MNBA.

No catálogo da Exposição de 1891 ainda aparece citado como "professor honorário da Academia"; já no de 1893, aparece como "foi professor honorário da extincta Academia das Bellas Artes" (grifo nosso), assim sendo, se estas afirmações forem tomadas como verdadeiras, pode significar que tenha morrido no intervalo de tempo, entre 1891 e 1893.

Estas dúvida sugerem pesquisas em cartórios da cidade do Rio de Janeiro e na Santa Casa de Misericórdia, para ver se existem registros de nascimento e morte deste pintor. Esta pesquisas deverão ser realizadas pessoalmente, uma vez que por telefone e por e-mails enviados, nada foi encontrado.

\footnotetext{
${ }^{6}$ http:/ / www.museuhistoriconacional.com.br/mh-i-01b.htm

7 Vale assinalar que discorda em um ano daquele estabelecido por Debret, 1830.

8 ALMANAK DO MINISTÉRIO DA MARINHA, 1865-1866; 1869-1870. (Não foram encontrados no acervo do Serviço de Documentação da Marinha, aqueles referentes aos anos de 1867-1868).

${ }_{9}$ ADES,1999:33.
} 
Este artigo revela uma pequena parte da diversidade de focos da obra pictórica de José dos Reis Carvalho e pressupõe, desde já, sua grande importância para a História da Arte Brasileira e, porque não dizer, para a História da Arte Universal.

\section{Bibliografia e demais fontes de pesquisa}

ADES, Down - Os Artistas Viajantes, a paisagem e representações do Brasil. In: - O Brasil Redescoberto. Rio de Janeiro: Paço Imperial/Min. C. IPHAN, 1999.

ALEMÃO, Freire. Carta a João Brigido, 16-5-1860, in "Gazeta de Notícias”. Sexto suplemento, Fortaleza, 10-7-1928.

ALMANAK DO MINISTÉRIO DA MARINHA, organizado pelo respectivo quartel general, pelas diversas estações da repartição. Rio de Janeiro, 1865-1866; 1869-1870.

ASSIS JÚNIOR, Heitor - Relações de von Martius com Imagens Naturalísticas e Artísticas do Século XIX. (Dissertação de Mestrado) - Campinas: Unicamp, IFCH, 2004.

AYLA, Walmir. Dicionário de Pintores Brasileiros. Rio de Janeiro: Spala Editores Ltda., 1986, v.1, p. 178.

BARROSO, Gustavo - A Arquitetura dos Sertões. O Cruzeiro, Rio de Janeiro, 16-10-1948, pp. $22,23,24,32$ e 34.

BRAGA, Renato - História da Comissão Científica de Exploração. Fortaleza: Imprensa Universitária do Ceará, 1962.

BRAGA, Teodoro. Artistas e Pintores no Brasil. São Paulo: Editora Limitada, 1942.

DEBRET, J. B. Viagem Pitoresca e Histórica ao Brasil. São Paulo: Livraria Itatiaia Editora Ltda e UDUSP, 1978.

DEBRET, J. B. Voyage pittoresque et historique au Brésil, Paris: Firmin Didot Frères, 1834-9, 3v.

DUQUE-ESTRADA, L. Gonzaga - Arte Brasileira: Pintura e Escultura. Rio de Janeiro: H. Lombaerts \& Cia., 1888, p. 71, ed. aos c. de T. Charelli, Campinas, Mercado das Letras, 1995.

FERREZ, Gilberto. Iconografia do Rio de Janeiro. Rio de Janeiro: Casa Jorge Editorial, 2000.

GARCIA, Rodolfo - História das Explorações Científicas. In: - Dicionário Histórico, Geográfico do Brasil (Comemorativo do primeiro centenário da Independência). Introdução Geral, vol. I, cap. 25. Rio de Janeiro: Imprensa Nacional, 1922. 
GALVÃO, Alfredo. Catálogo das Exposições Gerais de Belas Artes 1841, 1843, 1845 e 1850 e Prêmios Outorgados. Rio de Janeiro:1965, p. 1 e 10.

LEVY, Carlos Roberto Maciel. Exposições Gerais da Academia Imperial de Belas Artes. Rio de Janeiro: Edições Pinacotheke, 1990, v.1.

LIVRO DE REGISTRO das Cartas dos Lentes e Professores da Academia das Guardas Marinhas (manuscrito), pertencente ao acervo do Serviço de Documentação da Marinha, Rio de Janeiro.

MEDEIROS, João. Dicionário de Pintores do Brasil. Rio de Janeiro: Irradiação Cultural, 1988.

MIGLIACCIO, Luciano - O Século XIX. In: Mostra do Redescobrimento: Arte do Século XIX. São Paulo: Assoc. 500 Anos Artes Visuais, 2000.

MUSEU D. JOÃO VI, Catálogo do Acervo de Artes Visuais. UFRJ, Centro de Letras e Artes Escola de Belas Artes, 1996: 32-33; 138-147. 